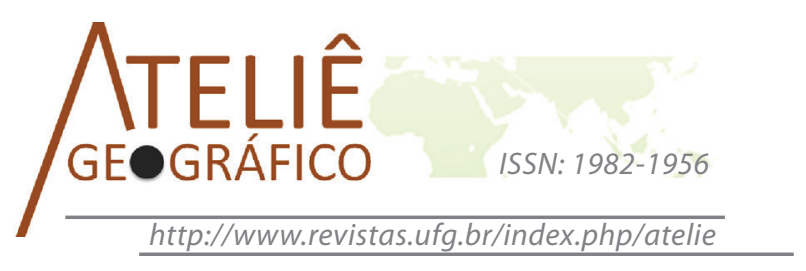

\title{
A agricultura familiar e a questão da sustenta- bilidade: alguns pontos para o debate
}

\author{
The family farming and the question of sustainability: \\ issues for debate \\ La agricultura familiar y la cuestión de la sostenibilidad: \\ cuestiones para el debate \\ Evandro César Clemente \\ Universidade Federal de Goiás - Regional Jataí \\ evandroclemente@yahoo.com.br
}

\begin{abstract}
Resumo
O trabalho busca levantar algumas questões para o debate acerca da problemática do desenvolvimento sustentável na agricultura brasileira, focando a agricultura familiar, destacando as condições, os limites e as possibilidades desta exercer a sustentabilidade. Defende-se o modelo das pequenas propriedades familiares, em contraposição ao agronegócio, como o ideal para exercer a sustentabilidade no campo. Apesar de haver concordância com esta tese, procura-se chamar atenção para a complexidade em que este assunto está envolto sob o sistema capitalista, já que mesmo nas pequenas propriedades encontramos problemas de degradação ambiental.
\end{abstract}

Palavras chave: desenvolvimento rural, desenvolvimento sustentável, agricultura familiar e agronegócio.

\begin{abstract}
The article raises some questions for the debate on sustainable development issues in Brazilian agriculture, focusing on family farming, highlighting the conditions, limits and possibilities of this exercise full sustainability. Defends the model of small family farms, as opposed to agribusiness, as the ideal to practice sustainability in the field. Although there is agreement with this thesis, we try to draw attention to the complexity of this subject is wrapped under the capitalist system, since even in small farms found problems of environmental degradation.

Keywords: rural development, sustainable development, agribusiness and family farming.
\end{abstract}




\begin{abstract}
Resumen
El artículo plantea algunas preguntas para el debate sobre temas de desarrollo sostenible en la agricultura brasileña, centrándose en la agricultura familiar, destacando las condiciones, límites y posibilidades de este ejercicio sostenibilidad completa. Defiende el modelo de las pequeñas explotaciones familiares, en contraposición a la agroindustria, como el ideal para practicar la sostenibilidad en el campo. Aunque existe un acuerdo con esta tesis, tratamos de llamar la atención sobre la complejidad de este tema está envuelto bajo el sistema capitalista, ya que incluso en pequeñas propriedad ha sido encontrado problemas de la degradación ambiental.
\end{abstract}

Palabras clave: desarrollo rural, el desarrollo sostenible, la agricultura familiar y agronegocios.

\title{
Introdução
}

Inicialmente será debatida a proposta do desenvolvimento sustentável, que por sua vez, é bastante vaga e imprecisa, carecendo de precisão teórica. O principal objetivo do trabalho, portanto, é discutir a questão da sustentabilidade na agricultura sob o sistema capitalista, tomando como foco de análise a realidade brasileira, que, apesar da enorme diversidade de sistemas produtivos, apresenta oficialmente dois "modelos": a agricultura familiar e o agronegócio.

Será analisada a situação da produção agropecuária brasileira e as questões que envolvem a busca da sustentabilidade sob o sistema capitalista. Parte-se do pressuposto que as pequenas propriedades familiares constituem-se no "modelo" mais adequado para exercer a sustentabilidade. Contudo, em trabalho de campo, verificou-se que as unidades de produção familiar também apresentaram problemas relativos à degradação ambiental, o que torna a questão bastante complexa, suscitando assim amplo debate. O objetivo não é esgotar a discussão, mas sim chamar atenção para questões que devem ser levadas em conta neste debate e contribuir para estimular e aprofundar o debate acerca da temática.

A pesquisa apresentada é resultado parcial da Tese de Doutorado em Geografia defendida no ano de 2011 na FCT/UNESP de Presidente Prudente e intitulada "O Programa Estadual de Microbacias Hidrográficas no contexto do desenvolvimento rural da Região de Jales". Para a consecução da pesquisa, foi realizado levantamento bibliográfico acerca do tema e também de dados de fonte secundária junto ao IBGE, além de trabalho de campo nos municípios de Jales, Urânia, Palmeira d' Oeste e Santa Albertina, que integram o Escritório de Desenvolvimento Rural de Jales (EDR), regionalização efetuada pela Secretaria Estadual da Agricultura de São Paulo por meio da Coordenadoria de Assistência Técnica Integral (CATI). Houve aplicação de formulários aos proprietários rurais e realização de entrevistas junto a técnicos responsáveis pela implementação e acompanhamento do programa de microbacias.

A Região de Jales, por sua vez, está localizada na porção noroeste do Estado de São Paulo e apresenta singularidades em seu espaço agrário, como uma estrutura fundiária desconcentrada, o predomínio de pequenas propriedades familiares e da policultura, tendo como destaques a fruticultura e a pecuária leiteira. 
$\mathrm{Na}$ primeira parte do artigo será debatida a questão do desenvolvimento sustentável no capitalismo e depois será focada tal questão para a agricultura brasileira.

\section{A questão do desenvolvimento sustentável no capitalismo}

Em 1986, como resultado de uma série de seminários a respeito de estilos alternativos de desenvolvimento pelo Programa das Nações Unidas para o Meio Ambiente, surgiu o relatório Our common future (Nosso futuro comum), que, mais tarde, ficou conhecido como Relatório Brundtland, em 1987. Neste relatório, são estudados os problemas mais críticos em relação ao desenvolvimento e o meio ambiente e são indicadas propostas de solução. Na ocasião, foi divulgada a noção de desenvolvimento sustentável como aquele "que responde às necessidades do presente sem comprometer as possibilidades das gerações futuras de satisfazer suas próprias necessidades" (CMMAD, 1988).

De acordo com Montibeller Filho (2008), foi na Conferência Mundial sobre a conservação e o desenvolvimento (Ottawa, Canadá, 1986), que o conceito de desenvolvimento sustentável foi colocado como um novo paradigma que:

[...] pressupõe, portanto, um conjunto de sustentabilidades; estas podem ser sintetizadas no seguinte trinômio: eficiência econômica, eficácia social e ambiental. $\mathrm{O}$ cumprimento simultâneo desses requisitos significa atingir o desenvolvimento sustentável (...) (MONTIBELLER FILHO, 2008, p. 59, grifo nosso).

Apesar do lançamento das premissas do desenvolvimento sustentável, em meados dos anos 1980, nas Conferências de Estocolmo (1972) e na Rio 92, a degradação do ambiente no mundo avançou de maneira constante, colocando em xeque a existência humana e da vida em geral no planeta, que por sua vez, dependem do bom funcionamento dos ecossistemas.

Desta forma, não há como negar que “(...) Essa crise [ecológica] é consequência direta de nossos comportamentos e modos de produção e consumo" (DUPAS, 2008, p. 76). Ainda de acordo com o autor supracitado, devemos levar em conta que é impossível haver crescimento econômico sem utilizar recursos naturais e sem gerar resíduos sólidos, o que necessariamente induz à ampliação dos impactos ambientais e dos conflitos distributivos. Diante dessa questão, os chamados "otimistas" acreditam que o capitalismo, por meio da busca pelo lucro, inclui o interesse público e, assim, incorporará estes custos, encontrando formas de viabilizar a sustentabilidade ambiental (DUPAS, 2008).

Por outro lado, Foladori (2001) e Montibeller Filho (2004) compreendem que o modo de produção capitalista, pelas suas características inerentes, como a busca incessante pela exploração da mais-valia social e dos recursos naturais, eleva-o à condição de uma utopia, havendo a necessidade de lutas populares visando frear, regular o ímpeto capitalista na sua voracidade em destruir recursos naturais e explorar a força de trabalho. Dupas (2008) demonstra que, pelas suas características inerentes, o capitalismo tem apresentado dificuldades em incorporar os custos ambientais. 
O conceito de desenvolvimento sustentável tem sido fortemente aceito e adotado em políticas públicas e nas diretrizes de grandes corporações. Isso se deve ao fato de que ele não impôs limites ao máximo de consumo aceitável, bem como reconheceu a necessidade da manutenção do crescimento econômico em bases 'sustentáveis', tanto para os países desenvolvidos, quanto para os subdesenvolvidos (HESPANHOL, 2008). Além disso, trouxe junto à noção de desenvolvimento, que tende a ser universalmente aceita, pois traz embutida a ideia de progresso e de melhorias.

O elevado padrão de consumo das populações dos países do Norte e das elites do Sul ainda permanece, o que tem contribuído para uma forte dilapidação dos recursos naturais, persistindo o desmatamento de florestas nativas, o desperdício de recursos pelo manejo inadequado e a ampla utilização de combustíveis fósseis, como o carvão e o petróleo. Cabe destacar que, neste último caso, o modelo fossilista permanece ainda muito em função do lobby exercido pelas grandes corporações petrolíferas.

O crescimento econômico, apesar das críticas e dos problemas sociais e ambientais que se acumulam, na prática, ainda, é fortemente defendido para que ocorra a qualquer custo, mesmo que, muitas vezes, de maneira velada ou nem tanto, pelos agentes hegemônicos do capitalismo. Vide a pressão que as grandes empresas estadunidenses, ligadas direta ou indiretamente ao petróleo, fizeram ao governo daquele país pela não assinatura do Protocolo de Kyoto em 1997, que implicaria obviamente em reduzir a queima de combustíveis fósseis e, assim, diminuir o nível de atividade econômica, o que resultaria inevitavelmente em perdas e prejuízos econômicos às grandes corporações.

Para Buarque (2008), a proposta de desenvolvimento sustentável é generosa, mas difícil e complexa de ser colocada em prática, por envolver mudanças estruturais e contar com resistências sociais e políticas fortes, decorrentes de privilégios e hábitos consolidados, principalmente nos países e segmentos sociais privilegiados. Prosseguindo, o autor destaca que “(...) é necessário promover mudanças profundas na essência mesma do modelo de desenvolvimento, principalmente no padrão tecnológico, na estrutura de renda e no padrão de consumo dominante da sociedade (...)" (BUARQUE, 2008, p. 69 grifos do autor). O autor ressalta que a sustentabilidade ambiental é atingível mesmo numa economia de mercado, demonstrando que vários avanços já foram realizados em direção à sustentabilidade, sobretudo na esfera tecnológica.

Foladori (2001), por sua vez, procura demonstrar que o sistema capitalista e o desenvolvimento sustentável são incompatíveis, havendo sérios limites para atingilo. Para ele, as propostas de desenvolvimento sustentável limitam-se a ver o problema ambiental somente pelo ângulo da questão técnica, tecnológica, evitando atingir a raiz dos problemas, que são as relações capitalistas de produção. Em sua opinião, “[...] é a forma social de produção e não seu conteúdo material e técnico que determina o comportamento em relação à natureza" (FOLADORI, 2001, p. 108). Além disso, cabe destacar, que em virtude da existência de uma sociedade classista no capitalismo, o poder de intervir no ambiente e depredá-lo está concentrado nas mãos dos detentores dos meios de produção.

Leitura muito semelhante acerca da questão é realizada em Montibeller Filho (2008). Para este: 
Sabe-se que o capitalismo avançado é um sistema que tende à produção de uma quantidade enorme de mercadorias. É ele impulsionado por uma dinâmica sintetizada no avanço tecnológico, aumento da produtividade e investimentos (...) - que implica produzir volumes sempre maiores de mercadorias como forma de obter lucro e garantir a valorização e acumulação de capital (...) (MONTIBELLER FILHO, 2004, p. 257-258).

Em razão disso,

(...) Em lugar de maior prosperidade geral, para que a engrenagem da acumulação funcione, assiste-se a um sucateamento contínuo de produtos em escala global, o que gera imenso desperdício de matérias-primas e recursos naturais ao custo imenso da degradação contínua do meio ambiente e da escassez de energia. É a opção privilegiada e inexorável pela acumulação de capital, em detrimento do bem-estar social amplo, gerando mais concentração de renda e poder e mais informalidade. (...) (DUPAS, 2008, p. 73).

O próprio Ignacy Sachs, um dos responsáveis pela formulação da noção do desenvolvimento sustentável, alerta para o fato de que:

(...) O desenvolvimento sustentável é, evidentemente, incompatível com o jogo sem restrições das forças do mercado. Os mercados são por demais míopes para transcender os curtos prazos (Deepak Navyar) e cegos para quaisquer considerações que não sejam lucros e a eficiência smithiana de alocação de recursos (...) (SACHS, 2008, p. 55).

O capitalismo se caracteriza por imprimir um ritmo acelerado de predação dos recursos naturais. Isto se dá por conta da criação artificial de necessidades do sistema, a partir da diversificação de produtos e mercadorias a serem ofertados aos indivíduos como forma de expandir o mercado consumidor e as margens de lucro. Assim, a velocidade de transformação das matérias primas em produtos que são consumidos e, depois, viram lixo, tem crescido de forma alarmante, de forma que os ciclos naturais não conseguem se autorregenerar, provocando escassez de recursos e aumento do lixo e das diversas formas de poluição do ambiente.

Pela sua imprecisão e amplitude, o desenvolvimento sustentável tem sido apropriado por diferentes maneiras e por distintos grupos sociais, como, inclusive, vem servindo aos agentes hegemônicos do capitalismo. Grupos empresariais têm percebido esta possibilidade e o utilizado para agregar valor aos produtos (ecologicamente corretos), à propaganda, ao ecomarketing, de maneira a disseminar uma imagem de responsabilidade ambiental. Contraditoriamente, o capitalismo cooptou este discurso para si, que, doravante, passou a servir aos desígnios deste modo de produção, como mais uma ideologia a seu serviço, porém, longe de equacionar efetivamente a questão.

Entende-se que isto esvaziou o seu significado e, simultaneamente, tornou possível o fato de o desenvolvimento sustentável estar presente no discurso de inúmeros agentes sociais situados em variadas posições, inclusive contraditórias, mas que, aparentemente, têm suas preocupações convergindo para o mesmo ponto central. Exemplo disso é a preocupação que o desenvolvimento sustentável tem despertado em 
setores da sociedade, que vão desde as políticas dos organismos multilaterais (ONU, FMI, Banco Mundial), líderes empresariais, chefes de Estado, militantes de movimentos sociais e ecológicos, acadêmicos, chegando até aos ecologistas mais radicais.

Sob esta estratégia mercadológica, têm surgido produtos ecologicamente corretos, como, no caso da agricultura, os orgânicos, produzidos sem defensivos agrícolas e/ou agrotóxicos e vendidos no mercado a preços normalmente superiores aos produzidos de maneira convencional. Percebe-se com isso que o capitalismo tem uma capacidade muito grande de engendrar o que, em tese, seria um limite à sua expansão e revertê-lo numa estratégia em seu favor.

As propostas para lidar com o imenso desafio ambiental começam a surgir. Mas, da mesma forma como no caso do desemprego e da exclusão - em que o capital reagiu com a cosmética mercadológica da "responsabilidade social da empresa" -, a tendência inicial parece semelhante (empresas "verdes", responsabilidade ambiental, adição de etanol à gasolina, etc.). Mas ações compatíveis com a escala e a gravidade do problema exigem modificações profundas no modelo produtivo dominante e seus modos de fabricação (...) (DUPAS, 2008, p. 77).

O conceito de desenvolvimento sustentável está envolto numa "armadilha conceitual", que busca focar questões de ordem técnico-ambientais, desviando de questões não menos importantes, como as de âmbito social, econômico e cultural (no caso os estilos de vida, consumo etc.).

Ignacy Sachs (2008) chama atenção para o fato de que o desenvolvimento sustentável não se restringe apenas à sustentabilidade ambiental, pois há outras dimensões não menos importantes, tais como a social, a econômica e a cultural. $\mathrm{O}$ autor destaca que o social "vem na frente", "por se destacar como a própria finalidade do desenvolvimento, sem contar com a probabilidade de que um colapso social ocorra antes da catástrofe ambiental;", (p. 71).

Verifica-se que o capitalismo, apesar do marketing empresarial e a estratégia de buscar medidas técnicas vinculadas às preocupações de cunho ambiental, apresenta uma lógica antiecológica e depredadora do ambiente, nunca antes vista na história da humanidade, de modo que a superação das desigualdades sociais e a resolução dos problemas ambientais têm-se tornado cada vez mais difíceis.

Para atingir o desenvolvimento sustentável, portanto, é necessário fortalecer a luta, por meio de uma sociedade civil organizada e de um Estado forte, visando resguardar os interesses coletivos em detrimento dos interesses deletérios do capital sobre o meio ambiente.

Existe uma corrente de pesquisadores que enfatizam que a crise ecológica, com a qual a humanidade hoje se defronta, reside no caráter limitado dos recursos naturais, devendo ter necessidade de conter o crescimento populacional. Estes adotam uma postura muito próxima à teoria malthusiana, pois, na verdade, a crise ecológica é gerada pelo superconsumo dos ricos, de modo que os pobres são os que mais sofrem os efeitos da devastação ambiental que, por sua vez, viabiliza este superconsumo dos mais abastados. 
Não há preocupação em garantir efetivamente que os recursos naturais disponíveis satisfaçam as necessidades elementares de todos os indivíduos, por meio de uma distribuição mais equitativa da riqueza. Isso revela que a questão também passa pela organização social e distribuição da riqueza e não somente no limite dos recursos naturais.

Em realidade, observamos que, apesar da enorme problemática ambiental gerada pela degradação sob o capitalismo, têm ocorrido alguns avanços, obtidos por meio da pressão dos movimentos ecológicos populares, obrigando o mercado capitalista a absorver, mesmo que de forma parcial, os chamados custos ambientais que ele mesmo gera. Dentre estes avanços, poderíamos citar a emergência de legislações ambientais em vários países do mundo (MONTIBELLER FILHO, 2008).

Fazendo um balanço da problemática e da discussão e das ações engendradas pelo desenvolvimento sustentável, desde a sua proposição até o momento, Hespanhol (2008) averiguou que os poucos avanços obtidos ficaram restritos à dimensão ambiental, enquanto que, as demais dimensões (social, política, econômica e cultural), permaneceram no nível da retórica. Sendo assim, reconhecemos que muitos dos "avanços técnicos" obtidos em relação à conservação ambiental, podem estar ocorrendo com a preocupação de "solucionar", adiar, parcialmente, é claro, os limites ecológicos para o atual sistema.

A concepção do crescimento econômico, linear e contínuo, que deve ser buscado principalmente por meio da industrialização, redundou em intensos reflexos sobre a agricultura, à qual coube exercer determinadas funções, para viabilizar o projeto industrializante nos países subdesenvolvidos como o Brasil. Com o grande surto industrial verificado no período pós guerra, que elevou o crescimento da economia mundial, os países subdesenvolvidos, dentre eles o Brasil, vislumbraram neste período a oportunidade de superarem a condição de subdesenvolvidos, por meio de políticas fomentando a industrialização e o crescimento econômico.

\section{A questão do desenvolvimento sustentável na agricultura e o papel da agricultura familiar}

Seguindo, portanto, as opções político ideológicas adotadas com o Golpe Militar de 1964, coube à agricultura brasileira algumas "tarefas", como: liberar mão de obra para o setor industrial, fornecer produtos alimentícios e matérias primas, transferir capital, ampliar a disponibilidade de divisas, demandar produtos industrializados e aumentar as exportações. Houve assim, a implantação e a disseminação do pacote tecnológico da Revolução Verde, visando auferir ganhos de produtividade com a utilização crescente de insumos químicos e mecanização agrícola.

O padrão de desenvolvimento adotado foi fortemente homogeneizador, sob o ponto de vista técnico e cultural, por conta da adoção de pacotes tecnológicos que induziram a processos produtivos ditos modernos, desconsiderando a diversidade ambiental e cultural existente no vasto território brasileiro. Também, não houve preocupações referentes à minimização dos impactos ambientais ou sociais que foram gerados. 
O Estado atuou decisivamente concedendo crédito subsidiado a grandes e médios produtores rurais e também a indústrias. Para isso, foram criados o Sistema Nacional de Crédito Rural (SNCR) e o Fundo Geral para a Indústria e Agricultura (FUNAGRI). Portanto, o crédito rural foi o principal instrumento utilizado pelo Estado, para promover a utilização cada vez maior de insumos modernos e consolidar as relações intersetoriais da agricultura e da indústria.

Como resultado, avançou a industrialização do campo, sob o comando dos complexos agroindustriais, em que a indústria, cada vez mais, passou a dominar os processos produtivos no campo, direta ou indiretamente, transformando a agricultura num ramo particular da indústria. Agravou-se também o êxodo rural e o inchaço nas periferias das grandes metrópoles, além do que o emprego no campo foi fortemente precarizado com a expansão do trabalho assalariado (boia fria) (GRAZIANO DA SILVA, 1999).

Fazendo um balanço dos efeitos da Revolução Verde na agricultura brasileira, Menezes constatou que,

\begin{abstract}
A modernização impôs um enorme dano ambiental pela exploração inadequada dos recursos naturais, a erosão do solo, a perda de fertilidade e sedimentação dos rios e o uso indiscriminado de fertilizantes, inseticidas e herbicidas. Além disso, a Revolução Verde aumentou a desigualdade no meio rural, pois beneficiou apenas os produtores de maior renda, além de tornar as culturas mais vulneráveis a pragas (MENEZES, 2007, p.202).
\end{abstract}

Assim, significativa parte dos efeitos nefastos que por ora foram apresentados, são reflexos diretos do paradigma de desenvolvimento (desenvolvimentismo) implantado no país (incluindo a agricultura). "Em nome do progresso, os agroecossistemas foram transformados, as culturas tradicionais foram distorcidas e as estruturas sociais tiveram suas bases modificadas" (MENEZES, 2007, p. 202).

Todo este processo redundou na exacerbação de problemas de ordem socioeconômica, como a intensificação da concentração fundiária, aumento das desigualdades sociais no campo, expropriação dos pequenos proprietários, superexploração da mão de obra rural a partir da expansão do trabalho assalariado temporário, em condições bastante precárias (bóias frias), que também resultou na geração de impactos ambientais, a começar pelo uso indiscriminado de agrotóxicos, insumos químicos e do manejo inadequado dos solos.

Estes fatores, por sua vez, contribuíram para aprofundar as desigualdades socioeconômicas no rural, bem como possibilitou o rebaixamento geral dos níveis salariais, tanto no campo quanto nas cidades, sendo que, nestas, o aporte constante de massas de trabalhadores oriundos do campo, elevou a oferta de mão de obra urbana e ajudou a deprimir os níveis salariais, elevando o desemprego e o subemprego, estando diretamente ligado à precarização das condições de vida dos trabalhadores.

Em relação aos impactos ambientais gerados na agricultura pelo modelo baseado na revolução verde, estes se aprofundaram a partir do uso crescente de modernas tecnologias e insumos, como herbicidas, inseticidas, pesticidas, fungicidas, corretivos de 
solo e outros, de maneira desordenada e excessiva, ou seja, indiscriminada (RUEGG et al, 1987). Ehlers (1999), por sua vez, demonstra a intensificação dos processos erosivos, a redução do potencial hídrico e a contaminação de agricultores, solos, animais, água e alimentos por agentes químicos.

Mesmo antes do período de "modernização" da agricultura, em virtude do caráter imediatista e predatório da ocupação do território nacional (HESPANHOL, 2007), o manejo do solo nas culturas comerciais no Brasil já apresentava problemas, vide o caso da cafeicultura, que, a partir do esgotamento dos solos na região do Vale do Paraíba, nas encostas das serras da Mantiqueira e do Mar, migraram em direção ao Oeste Paulista e Norte do Paraná, em busca de solos virgens e férteis.

Este modelo predatório de produção agrícola não se restringiu apenas à cafeicultura no Brasil, mas em diversos momentos da história econômica e em diferentes regiões do país, observou-se e ainda constata-se a presença de modelos predatórios, como na pecuária, na soja, na laranja, no algodão, entre outros.

Ruegg et al (1987) salientam que o uso excessivo de agrotóxicos, nos últimos anos na agricultura brasileira, levou à contaminação de alimentos, como o leite, a carne, as hortaliças, as frutas, os grãos, cujas análises revelaram muitas vezes a presença de resíduos químicos acima dos limites tolerados, resultando no acúmulo de resíduos em seres humanos e seus possíveis efeitos cancerígenos.

Além da possibilidade de causar câncer em humanos, a exposição às doses baixas de agrotóxicos tem acarretado o surgimento de muitos sintomas, doenças e intoxicações constatadas como: lesões hepáticas, lesões renais, neurite periférica, ação neurológica retardada, atrofia testicular, esterilidade masculina, cistite hemorrágica, hiperglicemia, hipertermia, diminuição das defesas orgânicas, fibrose pulmonar irreversível, reações de hipersensibilidade (asmas e alergias), teratogênese e mutagênese.

O avanço do processo de "modernização" da agricultura gerou a especialização produtiva dos proprietários rurais, quebrando o equilíbrio sustentável das pequenas propriedades rurais que se pautavam pela policultura, combinando a produção animal e vegetal, a autossuficiência em energia, o baixo custo do processo produtivo, o conhecimento cultural local do produtor rural e a adequação à diversidade e às condições ambientais regionais.

A modernização favoreceu a especialização da agricultura, impondo um padrão homogêneo e, com isso, disseminou-se fortemente a monocultura pelas terras do país, como a soja, o algodão, o milho, a cana de açúcar, entre outros produtos, em que o grande capital tem buscado adequar a produção agrícola a um esquema/modelo cada vez mais próximo do industrial.

Este padrão predominante de produção agrícola no país, guardadas as devidas diferenças e especificidades temporais e espaciais, tem sido edificado no mesmo padrão iniciado há mais de quinhentos anos, com a descoberta do país, em que Portugal produzia cana de açúcar no nordeste brasileiro, em grandes propriedades, plantation (monocultura), trabalho escravo e voltado para exportação. 
Apesar da abolição da escravatura, há mais de cem anos, ainda, atualmente, no país, tem sido comum a polícia ou as comissões do Ministério do Trabalho encontrarem formas de trabalho análogas à escravidão nas regiões Norte, Centro-Oeste e mesmo na Sudeste, que vem apresentando, na última década, um forte avanço da monocultura da cana de açúcar para a produção de açúcar e álcool.

Nas monocultoras agrícolas, por conta da simplificação genética, desencadeouse uma série de problemas ambientais, como proliferação de pragas, desequilíbrios ambientais, que requerem a aplicação sistemática de agrotóxicos, que por sua vez acabam ocasionando ainda mais desequilíbrios.

Podemos observar, como resultado direto, o fortalecimento no Brasil do denominado "agronegócio", pautado na produção monocultora e que apresenta elevada tecnificação, com alta competitividade no mercado internacional. Porém, toda essa competitividade ocorre à custa de processos espúrios de produção, como a superexploração da mão de obra e a forte degradação dos recursos naturais, como os solos e as águas, como consequência do emprego destes sistemas produtivos agrícolas fortemente predatórios.

O modelo monocultor do agronegócio foi imposto "de fora", por meio da "necessidade" que o país tinha de pagar a dívida externa, a partir da produção e exportação de produtos primários para gerar divisas. Assim, o Brasil ainda depende muito da exportação de soja, carne e minérios, para gerar superávits na sua balança comercial.

Por outro lado, constata-se a existência de um significativo número de pequenos proprietários rurais que não encontram alternativas para garantir uma sobrevivência digna no campo. O processo de "modernização" da agricultura, do ponto de vista do pequeno proprietário rural, foi bastante nocivo, de maneira que a sua renda tendeu a declinar, piorando suas condições de sobrevivência.

Com a renda em declínio e o crescente aumento dos custos de produção, os pequenos proprietários rurais migraram em direção às cidades e os que permaneceram no campo, enfrentam sérias dificuldades em continuar produzindo.

O processo de "modernização" no Brasil foi fortemente seletivo e excludente, o que não possibilitou uma reestruturação do modelo fundiário. Pelo contrário, houve uma intensificação da concentração da propriedade da terra, propiciando as condições necessárias para a expansão das chamadas grandes empresas agrícolas "modernas" monocultoras, que, sob o ponto de vista ambiental em geral, são fortemente predatórias.

O fato é que desenvolvimento sustentável tem encontrado sérias dificuldades para ser alcançado sob o modo de produção capitalista, já que a lógica deste é de externalizar os custos sociais e ambientais de produção (MONTIBELLER FILHO, 2008; FOLADORI, 2001). Contudo, tais autores ressaltam que a sustentabilidade plena pode ocorrer em casos isolados, em algumas situações específicas.

As mudanças estruturais necessárias esbarram nos interesses políticos e econômicos dos setores dominantes da sociedade, que tendem a pressionar as estruturas políticas para a manutenção de práticas fortemente lucrativas para si, porém, predatórias 
para o meio ambiente e excludentes para significativa parcela da sociedade. Portanto, para se alcançar o desenvolvimento rural e a sustentabilidade, é preciso construir e desconstruir consensos, conforme salienta Brandão (2007), ou seja, lutar contra interesses existentes que vão na contramão da busca pela sustentabilidade.

Originalmente, as preocupações com a questão ambiental na agricultura vieram à tona a partir de problemas ocorridos na Europa, como o mal da vaca louca, a gripe aviária e a poluição crescente das águas e solos por defensivos agrícolas, como pesticidas e nitratos, nos anos 1970 e 1980. Doravante, a União Europeia passou a priorizar políticas de cunho ambiental, em detrimento das de caráter produtivista, até então predominantes.

A noção de agricultura sustentável traz distintos posicionamentos teóricos. Para Hespanhol (2007), as empresas ligadas ao pacote tecnológico da Revolução Verde adotam uma perspectiva, enquanto que, as organizações não governamentais (ONGs), mais ligadas aos movimentos sociais e ambientalistas, se posicionam de forma distinta. As empresas defendem o modelo do agronegócio (monocultura) e as ONGs, por sua vez, defendem a agricultura familiar.

Em outras palavras, a busca da sustentabilidade na agricultura pode se dar de duas maneiras: na primeira versão dominante (empresas do pacote da revolução verde), acredita-se que o desenvolvimento científico e tecnológico, como a biotecnologia, pode superar as barreiras biológico-naturais impostas à produção agrícola. Esta aumentaria a produtividade e a produção, ao mesmo tempo que retiraria a pressão sobre os recursos naturais, atingindo a sustentabilidade. Essa visão está em consonância com os interesses das grandes empresas vinculadas ao agronegócio.

Esta concepção é defendida por aqueles que acreditam que a sustentabilidade pode ser alcançada estritamente por meio de soluções técnicas ou tecnológicas, sem atentar para questões sociais, políticas, econômicas e culturais.

O segundo posicionamento, de forma distinta, visa atingir a sustentabilidade por meio de mudanças estruturais do quadro agrário atual, como reformulações na estrutura da propriedade da terra, busca da diversificação produtiva em unidades de menor escala, valorização da cultura e dos conhecimentos tradicionais dos proprietários rurais, compatibilizando, assim, o ritmo das atividades agrícolas com o ritmo dos ciclos e processos naturais.

Apesar da vasta extensão territorial do Brasil e da grande heterogeneidade de sistemas produtivos presentes na agricultura brasileira, coexistem dois modelos distintos: o denominado "agronegócio" e a agricultura familiar. Mesmo correndo o risco de simplificar a realidade e ignorar a riqueza e a variedade das múltiplas formas de produzir e de inserir-se no mercado neste enorme território ocupado pela agricultura brasileira, adotaremos esta classificação que é tida como oficial, ou seja, é utilizada pelos órgãos governamentais na implementação das políticas públicas direcionadas ao campo brasileiro.

Esta situação é ratificada oficialmente pela existência do Ministério do Desenvolvimento Agrário (MDA), que é ligado às questões fundiárias, ao INCRA, aos movimentos sociais, remanescentes de quilombos, aos próprios agricultores familiares, 
ribeirinhos e populações tradicionais. Por outro lado, tem-se o Ministério da Agricultura, Pecuária e Abastecimento (MAPA) que é vinculado ao agronegócio.

Assad; Almeida (2004) demonstram que a sustentabilidade da agricultura, embora defendida por alguns setores da sociedade, ela é ainda utópica, pois a implementação de ações, práticas alternativas e manejos sustentáveis que permitam realmente uma atenuação dos danos ambientais, esbarram em interesses econômicos. Além disso, os autores chamam atenção para o fato de que a sustentabilidade tem sido vista apenas de forma restrita à questão ambiental, sem tocar na questão da sustentabilidade social.

Os grupos dominantes (latifundiários e grandes empresas) têm interesse que a questão seja vista apenas pelo seu viés ambiental-tecnológico, eximindo-os, assim, de uma pressão maior pela reforma agrária, de políticas de redistribuição de renda, de garantia de segurança alimentar, dentre outras, que mexeriam em seus privilégios e interesses. Desta forma, “(...) desde seus primórdios, as iniciativas em prol de uma agricultura mais sustentável reservam um lugar importante à tecnologia, aos processos e métodos de produção" (ASSAD; ALMEIDA, 2004, p. 8).

As ONGs e os movimentos sociais compreendem que um padrão de agricultura sustentável somente é atingido, quando ela é ecológica e socioeconomicamente viável, em que se tenha ao mesmo tempo, um modelo equitativo sob o ponto de vista social e econômico. Já para as empresas atingirem uma agricultura sustentável, basta a adoção de modernas tecnologias que viabilizem a produção sem comprometer os recursos naturais. No caso para as ONGs, são necessárias reformulações estruturais, de modo que ultrapassem os limites tecnológicos (HESPANHOL, 2007).

Na mesma direção, Caporal; Costabeber (2000) demonstram que, para atingir a sustentabilidade, deve-se engendrar também preocupações de caráter socioeconômico e cultural.

A tendência da monocultura é de expandir a sua produção, ampliando, cada vez mais a oferta e diminuindo seus preços. Deste modo, as margens de lucro têm sido cada vez menores, impelindo os produtores a adotarem tecnologias de elevado custo e a ampliarem a escala de produção, buscando diminuírem os custos unitários de produção. Por conta do predomínio deste paradigma de produção, torna-se inviável a produção agrícola em pequenas áreas e tende a reforçar a produção em grandes áreas, formando as monoculturas (HESPANHOL, 2007).

A expansão do agronegócio (revolução verde) no Brasil, de maneira dominante em diversos setores, deu-se a partir dos anos 1960, como na soja, na cana de açúcar, na laranja, no algodão, no café, na pecuária bovina de corte, entre outros. Essa produção ocorre em grandes propriedades altamente mecanizadas e com a utilização de trabalho assalariado, ou seja, numa lógica puramente capitalista, em que a produção de mercadorias tende a não ter limites (esquema $\mathrm{D}-\mathrm{M}-\mathrm{D}$ '). Exceção à regra ocorre no sul do país, onde a produção de soja e aves, por exemplo, se dá em grande parte com o emprego de mão de obra familiar.

Porém, o capitalismo, por conta de seu desenvolvimento desigual, contraditório e combinado, tem, paradoxalmente, possibilitado a existência e a permanência de 
um considerável número de pequenas propriedades rurais que subsistem produzindo fumo, frutas, leite, hortaliças, suínos, aves, entre outros produtos (OLIVEIRA, 2001) (MARTINS, 1995). Por conta do predomínio do trabalho familiar e do assalariamento, apenas em caráter temporário, reconhecemos que tais unidades de produção funcionam numa lógica distinta da puramente empresarial/capitalista, cujo objetivo primordial destas unidades de produção é a reprodução social da família, enquanto proprietários rurais (produção para valor de uso $\mathrm{M}-\mathrm{D}-\mathrm{M}^{\prime}$ ).

É importante reiterar a distinta lógica presente nas pequenas propriedades familiares, as quais destoam da lógica predominante, que é a incessante e infinita busca pelo lucro, em que o incremento da produção é um fim em si mesmo, ocasionando quantidades produzidas exageradas que, muitas das vezes, desconhecem os limites naturais ou de consumo.

Em face da insustentabilidade da produção em moldes puramente capitalistas (monocultura), muitos autores defendem a produção agrícola realizada em pequenas propriedades familiares. Por operar em menor escala, sob outra "lógica", pelo "apego" à terra que possuem os pequenos proprietários rurais, pela maior integração da produção à dinâmica natural em função da diversificação produtiva (pecuária bovina, suínos, aves, conjugados com a produção agrícola), tende a haver "maior harmonia" com o sistema e o ritmo da natureza. Isso tem chamado atenção de estudiosos e constituído, assim, uma "alternativa" frente à produção capitalista/monocultura, que apresenta um modelo fortemente predatório dos recursos naturais e, ao mesmo tempo, concentrador de renda.

Carmo (1998) corrobora esta afirmação e considera a agricultura familiar como o locus ideal para uma agricultura sustentável.

A produção familiar, dada as suas características de diversificação/integração de atividades vegetais e animais, e por trabalhar em menores escalas, pode representar o locus ideal ao desenvolvimento de uma agricultura ambientalmente sustentável. É fundamental, porém, que seja alvo de uma política estruturada e implementada para este fim. Um novo padrão de desenvolvimento definido pela autosustentabilidade, potencializa a participação da agricultura familiar na oferta agrícola, embora não seja um segmento homogêneo. (CARMO, 1998, p.15).

Além da autora supracitada, Caporal: Costabeber (2000) também apontam a agricultura familiar como locus ideal da produção sustentável na agricultura, operando numa lógica distinta da puramente capitalista.

Também exige compreender, desde o início, que a agricultura familiar é, ao mesmo tempo, unidade de produção, de consumo e de reprodução e que, portanto, funciona mediante uma lógica de produção combinada de valores de uso e de mercadorias, objetivando sua reprodução. Obviamente, se trata de uma lógica diferente daquela que impulsiona a agricultura capitalista. (CAPORAL; COSTABEBER, 2000, p.10).

Daí, a importância, por exemplo, da produção de subsistência, assim como a produção de bens de consumo em geral, que não costumam aparecer nas medições e 
estudos monetários convencionais, mas que são importantes no processo de reprodução social e nos graus de satisfação dos membros da família (COSTABEBER; CAPORAL, 2003).

Apesar de também reconhecermos e acreditarmos que o modelo baseado em pequenas propriedades rurais familiares, realmente apresenta melhores condições para exercer a sustentabilidade, do que as grandes propriedades monocultoras, não podemos cair no equívoco de adotarmos uma visão maniqueísta e estática, como se fossem dois modelos fechados, sendo um totalmente "sustentável" e outro "não sustentável". Já está explícito que consideramos o modelo monocultor fortemente insustentável pela grande predação que tem provocado ao meio ambiente. Por outro lado, em muitas pequenas propriedades rurais, apesar da maior capacidade de exercer a sustentabilidade, é possível também encontrar vários problemas de ordem ambiental, como desrespeito às áreas de preservação permanente (APP), utilização desenfreada de insumos químicos, manejos inadequados dos solos e águas, dentre outros.

Importante considerar que, apesar de funcionar sob uma lógica que não é puramente capitalista, a agricultura familiar tem seu funcionamento engendrado pela mesma, que indiretamente, por meio de vários mecanismos de mercado - subsunção formal (MARTINS, 1995) -, o capital mercantil, agroindustrial e bancário têm submetido os pequenos proprietários rurais familiares a uma grande exploração indireta, que impõe dificuldades e torna mais difícil a produção para estes.

Tanto o capital industrial à montante e à jusante do produtor rural, como os capitais mercantil e bancário conseguem abocanhar parte da renda gerada, mesmo quando o agricultor detém a propriedade da terra. Mesmo não havendo a expropriação do trabalhador e a sua consequente proletarização ("boias-frias"), os diferentes tipos de capital criam condições e mecanismos para apoderar-se de parte da renda da terra produzida (MARTINS, 1991 e 1995).

Buscando resistir e garantir a sua reprodução social, os pequenos proprietários buscam maximizar (otimizar) a exploração de sua exígua propriedade, como estratégia para auferirem maiores rendimentos que os viabilizem economicamente, enquanto proprietários de terra, evitando, assim, a expropriação.

Muitas vezes, a insuficiente extensão das terras exploradas por esta categoria de proprietários rurais e a situação de exploração a que estão submetidos, bem como a falta de recursos, falta de crédito adequado às suas necessidades, ausência de assistência técnica, de orientação e de políticas públicas efetivas destinadas a ampará-los, representam a nosso ver, os principais fatores desencadeadores, nesse caso, dos problemas ambientais. Buscando o aproveitamento "máximo" da pouca terra disponível, eles terminam por não respeitar a área de preservação permanente (APP), utilizam insumos visando "reduzir os custos de produção" e também não contam com recursos e/ou informações para a adoção de procedimentos e manejos, visando à correção do solo, a construção de terraços, a implantação de curvas de nível e outros.

No entanto, é importante esclarecer que, mesmo dentro do conjunto de proprietários rurais que podemos definir como agricultores ou proprietários familiares, existe uma variedade (heterogeneidade) muito grande de sistemas produtivos. 
Em trabalho de campo realizado no EDR de Jales (localização no Figura 01), foi possível verificar várias situações de problemas de manejo e de degradação de solos e águas em pequenas propriedades rurais nos vários municípios pesquisados em trabalho de campo. Foi possível averiguar solos erodidos, lixiviados, ausência de mata nas áreas de preservação permanente (APP), dentre outros problemas.
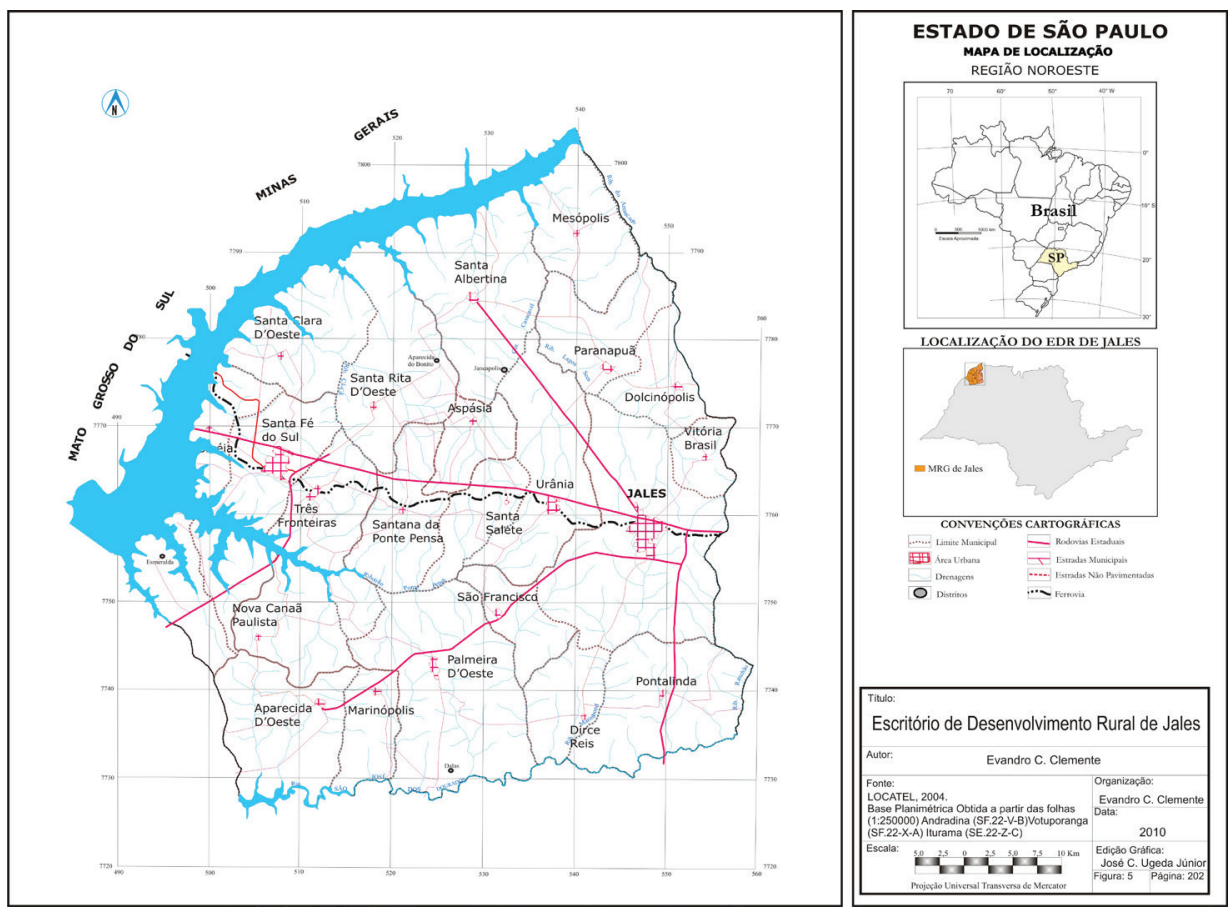

Figura 1. Localização do EDR de Jales-SP

Na Figura 2 ( $\mathrm{A}, \mathrm{B}$ e C) é possível observar a ausência de mata ciliar e os processos de assoreamento já em marcha. Na Figura 2 (A), referente ao córrego do Schmidt, no município de Santa Albertina, podemos notar, inclusive, a formação de "bancos de areia" já até cobertos por vegetação, além das "marcas" dos processos erosivos situadas pouco acima dos bancos de areia. Na Figura 2 (B), referente ao Córrego do Corvo, município de Palmeira d'Oeste, pode-se constatar a ausência da mata ciliar, com a pastagem ocupando o lugar que deveria ser destinado à mata, prejudicando então a conservação do curso d'água. Na Figura 2 (C), por sua vez, é possível também verificar a degradação ambiental, como a falta de mata ciliar, o assoreamento e a diminuição da lâmina d'água causados em consequência da ausência desta.

Já na Figura 2 (D) pode-se observar a pastagem degradada e o processo de lixiviação do solo, em decorrência da falta de manejo adequado da pastagem e do solo no Córrego do Ribeirão Lagoa, município de Jales. 

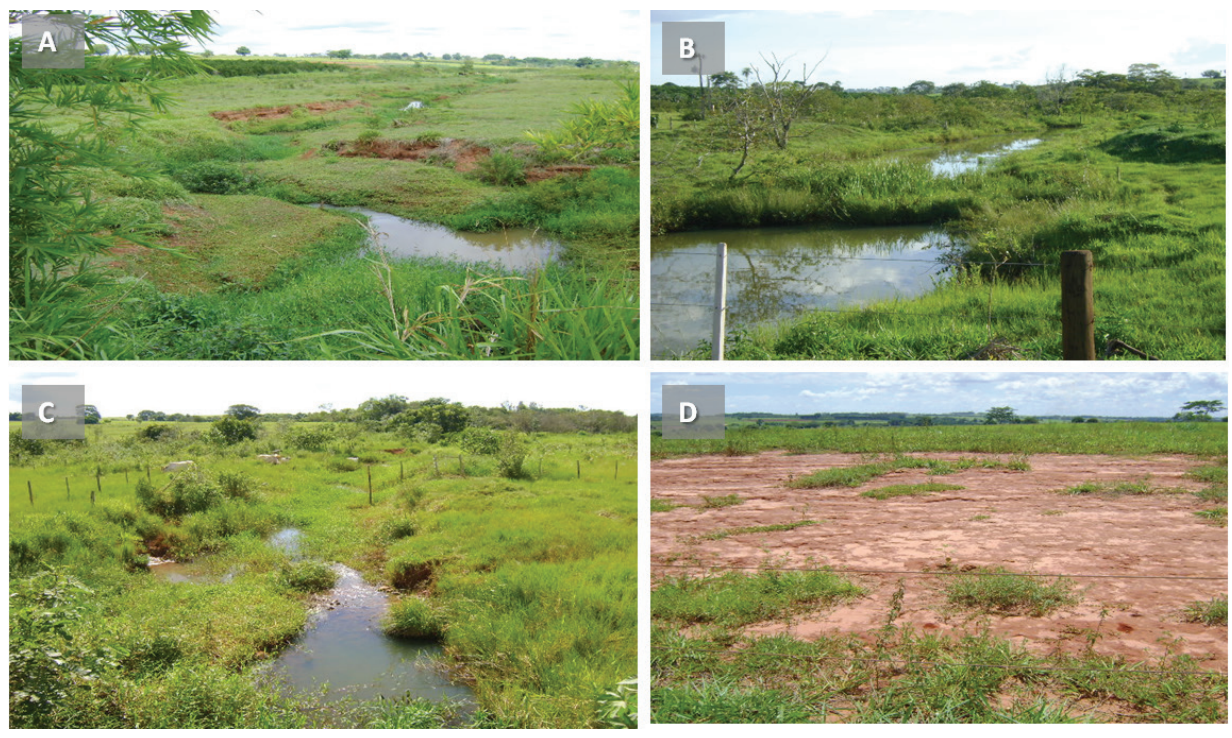

Figura 2. A) Ausência de mata ciliar e assoreamento no Córrego do Schmidt - município de Santa Albertina-SP. B) Ausência de mata ciliar no Córrego do Corvo, município de Palmeira dOeste. C) Ausência de mata ciliar e assoreamento no Córrego do Sucuri. D) Pastagem degradada e processo de lixiviação do solo no município de Jales-SP.

Fonte: Fotografias do autor (dez/2008).

As figuras mencionadas anteriormente demonstram a degradação ambiental presente também em pequenas propriedades familiares. Porém, a situação de "insustentabilidade" de parcelas dos agricultores familiares se deve à submissão desta à exploração indireta pelo capital. Visando sanar e/ou atenuar a degradação ambiental nesta, deveriam existir políticas públicas eficazes direcionadas a esta categoria de proprietários rurais, de modo a garantir condições adequadas à obtenção de renda satisfatória e acesso a conhecimentos, manejos e técnicas sustentáveis, que permitam assim, atenuar a pressão pela superexploração da terra e das águas, possibilitando reduzir também o uso de agrotóxicos e de fertilizantes. Há que se apontar também a falta de informação e conscientização dos proprietários rurais, no tocante à temática ambiental.

Cumpre ressaltar também que parte dos problemas ambientais apresentados tem como causa a resistência e falta de informação e consciência de alguns proprietários rurais. Em entrevista com técnicos, foi relatada a negativa de alguns proprietários rurais para a realização do plantio de mudas para recuperar a mata ciliar nas áreas de preservação permanente, bem como o cercamento destas. De acordo com eles, o argumento apresentado pelos proprietários rurais, era de que a cerca impediria o gado bovino de ter acesso à pouca vegetação que resiste no período de estiagem e, que serve de alimento ao rebanho nesta época do ano.

Deste modo, a busca da sustentabilidade esbarra na escassez de políticas públicas efetivas destinadas à agricultura familiar no país. Conforme demonstra Denardi 
(2001, p.57), “Quanto às políticas públicas para a agricultura, o que tivemos, de fato, nas últimas quatro décadas, foi principalmente a política agrícola, já que a política agrária foi sempre marginal ou inexistente".

Defendemos que a agricultura familiar deve ser fortalecida e expandida por meio de políticas públicas que tenham efetivo compromisso com a sustentabilidade, tanto no âmbito socioeconômico, quanto no ambiental. A agricultura familiar consegue absorver relativamente significativa quantidade de mão de obra, gera emprego e renda aos pequenos proprietários rurais e trabalhadores do campo, além de ter grande capacidade de gerar produtos e alimentos saudáveis.

Essa importância da agricultura familiar se reveste de um caráter ainda mais estratégico se levarmos em conta que a agricultura é o setor responsável diretamente pela dinâmica econômica em diversas regiões do país, em especial nos municípios situados no interior do país.

Corroborando a afirmação anterior, basta verificar os dados divulgados pela Fundação Instituto Brasileiro de Geografia e Estatística (FIBGE) no Censo Agropecuário de 2006. De acordo com os dados, a agricultura familiar perfaz 4.367.902 estabelecimentos rurais do país, que representam $84,4 \%$ do total (5.175.489 estabelecimentos), porém ocupa apenas 24,3\% (ou 80,25 milhões de hectares) da área dos estabelecimentos agropecuários brasileiros. Mesmo ocupando menor porção da área agricultável do país, responde por 38,0\% do valor da produção (ou 54,4 bilhões de reais).

Outro dado positivo tem sido a geração de ocupação e renda pela agricultura familiar, de modo que 12,3 milhões de trabalhadores ocupados no campo trabalham em estabelecimentos da agricultura familiar, o que representa $74,4 \%$ do total de ocupados no campo. Pelos dados, ainda se pode constatar que a agricultura familiar é mais rentável na utilização de suas terras, pois consegue gerar um valor de produção de $\mathrm{R} \$ 677,00$ por hectare, enquanto que as propriedades não familiares geram um valor de $\mathrm{R} \$ 358,00$ por hectare.

Além disso, ainda de acordo com Censo Agropecuário, a agricultura familiar é responsável pela segurança alimentar do país, à medida que é responsável pela produção da maior parte dos produtos alimentícios, como $70 \%$ do feijão, $87 \%$ da mandioca, $58,0 \%$ do leite, $46,0 \%$ do milho, $38 \%$ do café, $34 \%$ do arroz, $59 \%$ do plantel de suínos, $50 \%$ das aves, $30 \%$ dos bovinos e, ainda, $21 \%$ do trigo, sendo que a cultura com menor participação da agricultura familiar foi a soja (16\%), produto típico do agronegócio.

Estes dados vêm demonstrar que a produção da agricultura familiar é mais eficiente, a que mais gera emprego e renda e a que fornece a maior quantidade de alimentos aos brasileiros. Além disso, não podemos negar que existe um segmento da agricultura familiar que também contribui para as exportações, tornando a questão um pouco mais complexa, para aqueles que tendem a enquadrá-la como "agricultura de subsistência" ou que as exportações agrícolas são efetuadas apenas pelo denominado "agronegócio".

Hespanhol (2008) salienta que, por um lado, o agronegócio apresenta vantagens alocativas em relação à agricultura familiar, a maior escala de produção e o elevado nível 
tecnológico. Por outro, a agricultura familiar apresenta vantagens distributivas, como: grande capacidade de absorver mão de obra, ambientalmente menos agressiva (tem mais chances de exercer a exploração sustentável da agricultura).

Porém, apesar de entendermos que a pequena propriedade é o modelo mais apropriado para exercer a sustentabilidade, não podemos nos esquecer que a questão está envolta numa forte complexidade, pois, concomitantemente, apesar de operar numa lógica distinta da visão capitalista, os pequenos proprietários rurais também "servem" ao capitalismo, no caso, as grandes empresas agroindustriais. Sendo visível a degradação ambiental também em pequenas propriedades, visto que a exiguidade de terras muitas vezes leva os pequenos proprietários a desmatar toda a propriedade, não preservando e respeitando os limites exigidos nas margens dos cursos d'água como áreas de preservação permanente (APP).

Apesar das dificuldades em alcançar a sustentabilidade em todas as suas dimensões no capitalismo, consideramos extremamente válida a luta e as medidas adotadas para minorar os impactos ambientais, pois tem sido fundamental a pressão exercida sobre os governos e as empresas para que adotem condutas e políticas sustentáveis, procurando aprimorar as medidas existentes e adicionar outras. Para isso, é imprescindível a atuação do Estado impondo limites às ações predatórias das grandes empresas privadas por meio de leis e regulamentos. Também é imprescindível a sociedade organizada e cobrando o Estado e as empresas.

Cumpre ressaltar que recentemente vem surgindo um movimento muito importante e, de certo modo, significativo, na busca pelo desenvolvimento rural sustentável, em oposição aos princípios da revolução verde, que é a agroecologia. Este movimento encontra-se fortemente vinculado aos pequenos proprietários rurais, como os agricultores familiares, quilombolas, movimentos sociais, povos tradicionais, ONGs, que primam pela produção agrícola "orgânica" sem utilização de insumos químicos, nem agrotóxicos. Para Caporal; Costabeber (2000; 2002), a agroecologia constitui-se num novo paradigma produtivo para a agricultura.

\section{Considerações finais}

A opção do Governo e dos setores hegemônicos que imperam na agricultura brasileira, no caso as grandes empresas, os grandes proprietários rurais e os bancos têm sido pelo fortalecimento e consolidação do padrão produtivo da agricultura capitalista e de uma busca pela sustentabilidade por meio da "solução técnica ou tecnológica" na agricultura brasileira, desviando propositadamente a atenção para questões de ordem social, política, econômica e até cultural. Há um interesse muito forte destes segmentos em não colocar em debate a necessidade de uma reforma agrária no país. Assim, a agricultura familiar no Brasil, mesmo com a existência de políticas públicas destinadas a ela, ainda não tem sido contemplada de modo satisfatório, já que estas têm sido em geral insuficientes e inadequadas por diversas razões.

A situação de vulnerabilidade de significativa parcela dos pequenos proprietários rurais no Brasil se deve ao papel que lhe foi destinado pela classe dominante e o Governo 
brasileiro, que foi o de cumprir certas funções para viabilizar a acumulação de capital, como: possibilitar a produção de alimentos a baixo custo para a classe trabalhadora, produzir matérias primas e mercadorias a baixo custo em setores da produção agropecuária em que a mecanização não foi totalmente possível devido à questões técnico naturais, ou em que é mais vantajoso (lucrativo) ao capital deixar a produção ao cargo de pequenos proprietários rurais, como no caso do fumo, das frutas de mesa, etc. Isso torna possível o pagamento de baixos salários para a reprodução da força de trabalho urbana, alargando as margens de lucro dos empresários por um lado e, por outro, mantendo os pequenos proprietários rurais em más condições de sobrevivência.

É imprescindível que haja uma reforma agrária no país para que assim seja possível almejar a busca da sustentabilidade socioeconômica e ambiental no campo brasileiro. Com melhor distribuição da riqueza e da renda e amparados por efetivas políticas públicas, os pequenos proprietários rurais teriam maiores condições de produzir sem grandes alterações e/ou impactos no meio ambiente.

Pelos dados do IBGE apresentados ao longo do trabalho, constatou-se que a agricultura familiar constitui-se no padrão produtivo mais eficiente, tanto sob o ponto de vista ambiental, quanto no socioeconômico concomitantemente. Pois, por meio da policultura (diversificação produtiva) consegue estabelecer meios de produção menos agressivos ao ambiente, ao mesmo tempo em que é responsável pela maior parte dos alimentos produzidos para a população brasileira, gera mais emprego e renda, além de gerar maior valor de produção, mesmo ocupando uma área muito menor em relação às grandes propriedades.

Um ponto muito relevante nisso é o fato de operarem numa lógica distinta da empresarial capitalista, que por sua vez, não enxerga limite na sua busca incessante do lucro, tendendo a aumentar indiscriminadamente a produção de mercadorias, assim como o uso de insumos químicos, a exploração dos recursos naturais e do trabalho humano em seus processos produtivos, revelando aí uma lógica contrária às premissas do desenvolvimento sustentável. Já a agricultura familiar possui como objetivo precípuo garantir a reprodução da unidade familiar.

Apesar de reconhecermos o potencial em exercer a sustentabilidade no campo pela agricultura familiar, o que ocorre é que ela também vem apresentando significativos processos de degradação ambiental sob o sistema capitalista, o que tem inclusive alimentado discursos conservadores contrários à agricultura familiar. Mesmo sendo proprietários de terras, é preciso reconhecer que eles encontram-se submetidos à exploração capitalista por meios indiretos que os induzem a intensificarem o aproveitamento da pouca terra que possuem. Com o objetivo de se manterem na terra como proprietários rurais e diante do baixo preço recebido pela venda de sua produção, eles tendem a buscar aumentar a renda por meio da expansão da exígua área explorada e reduzir custos com o uso de insumos químicos em muitos casos sem orientação técnica adequada. O resultado disso é o não respeito às áreas de preservação permanente (APPs) e a degradação ambiental.

Além das medidas, ações e políticas de cunho técnico agronômica, seriam necessárias políticas integradas e articuladas também na esfera socioeconômica, no caso 
a realização de reforma agrária associada às políticas de geração de renda e emprego para os agricultores familiares. Contempladas a esfera socioeconômica e ambiental de forma simultânea, seria possível superar a visão hegemônica pelos agentes do capital, que tendem a enxergar a questão apenas pelo viés técnico ambiental e, assim vislumbrar atingir o desenvolvimento rural sustentável no campo brasileiro.

\section{Referências}

ASSAD, M. L. L; ALMEIDA, J. Agricultura e sustentabilidade: contexto, desafios e cenários. In: Revista Ciência \& Ambiente, n. 29, 2004. p.15-30.

BRANDÃO, Carlos Antônio. Território e desenvolvimento: as múltiplas escalas entre o local e o global. Campinas, Editora da UNICAMP, 2007.

CAPORAL, F. R; COSTABEBER, J. A;. Agroecologia e desenvolvimento rural sustentável: Perspectivas para uma nova Extensão Rural (2000). In: http://www. agroecologia.uema.br/publicacoes/AgroecologiaRGS.pdf acesso em 14 de dezembro de 2009.

CAPORAL, Francisco Roberto; COSTABEBER, José Antônio. Agroecologia. Enfoque científico e estratégico. In: Agroecologia e Desenvolvimento Rural Sustentável. Porto Alegre, v.3, n.2, abr./jun., 2002. p. 13-16

CARMO, Maristela S. do. A produção familiar como locus ideal da agricultura sustentável. In: Revista Agricultura em São Paulo, SP, 45(1), 1998. p. 1-15.

BUARQUE, Sergio C. Construindo o desenvolvimento local sustentável.

Metodologia de planejamento. Rio de Janeiro: Garamond, 2008.

COMISSÃO Mundial sobre Meio Ambiente e Desenvolvimento (CMMAD). Nosso Futuro Comum. Rio de Janeiro: FGV, 1988.

DENARDI, Reni Antonio. Agricultura familiar e políticas públicas: alguns dilemas e desafios para o desenvolvimento rural sustentável. In: Revista de Agroecologia e Desenv.Rur.Sustent.,Porto Alegre, v.2, n.3, jul./set.2001.

DUPAS, Gilberto. O impasse ambiental e a lógica do capital. In: DUPAS, Gilberto (Org.). Meio ambiente e crescimento econômico: tensões estruturais. São Paulo: Editora da UNESP, 2008.

FOLADORI, Guillermo. Limites do desenvolvimento sustentável. Trad. Marise Manoel. Campinas, Editora da UNICAMP, São Paulo, Imprensa Oficial, 2001.

GRAZIANO DA SILVA, J. O novo rural brasileiro. Campinas: Instituto de Economia/Unicamp, 1999. 153 p.

HESPANHOL, A. N. Origem, magnitude e territorialização do agronegócio no Brasil. In: III Encontro de Grupos de Pesquisa Sobre Agricultura, Desenvolvimento e Transformações Sociais, 2007, Porto Alegre. Anais do III Encontro de Grupos de Pesquisa Sobre Agricultura, Desenvolvimento e Transformações Sociais. Porto Alegre: UFRGS, 2007. 
HESPANHOL, A. N. Os programas de microbacias no Brasil. In: MARAFON, Gláucio José; PESSÔA, Vera Lúcia Salazar (Orgs.). Agricultura, Desenvolvimento e Transformações Socioespaciais: Reflexões interinstitucionais e constituição de grupos de pesquisa no rural e no urbano. Uberlândia: Ed. UFU, 2008.

MARTINS, J. S. Expropriação e violência: a questão política no campo. São Paulo: Hucitec, 1991.

MARTINS, J. S. Os camponeses e a política no Brasil. Petrópolis, Vozes, 1995.

MENEZES, Ana Virgínia Costa de. Sociedade sustentável: em busca de um caminho. In: MARAFON, G. J. ; RUA, J.; RIBEIRO, M. A. Abordagens teórico-metodológicas em geografia agrária. Rio de Janeiro: EdUERJ, 2007. 330 p.

MONTIBELLER-FILHO, G. O mito do desenvolvimento sustentável: meio ambiente e custos sociais no moderno sistema produtor de mercadorias. $3^{\mathrm{a}} \mathrm{Ed}$. Florianópolis: Editora da UFSC, 2008. 316 p.

OLIVEIRA, A. U. de. Agricultura brasileira: transformações recentes. In: ROSS, Jurandyr L. Sanches (org.). Geografia do Brasil. EDUSP, São Paulo,2001.

RUEGG, E.F. et al. Impacto dos agrotóxicos sobre o ambiente e a saúde. In: MARTINE, G.; GARCIA, R.C. (Org.) Os impactos sociais da modernização agrícola. São Paulo: Editora Caetés, 1987. cap. 7, p. 171-207.

SACHS, Ignacy. Caminhos para o desenvolvimento sustentável. Organização: Paula Yone Stroh. Rio de Janeiro: Garamond, 2008. 96 p.

Evandro César Clemente

Doutor em Geografia pela Universidade Estadual Paulista Júlio de Mesquita Filho, Faculdade de Ciências e Tecnologia (FCT), Campus de Presidente Prudente, e Professor dos cursos de Graduação e Pós-Graduação da Universidade Federal de Goiás, Regional Jataí.

Rua Riachuelo, $\mathrm{n}^{\circ} 1.530$. Setor Samuel Graham. Cep: 75804527 - Jataí, GO Brasil.

E-mail: evandroclemente@yahoo.com.br 